\title{
A BIOLOGIA EM OBRAS INFANTIS DE MONTEIRO LOBATO: MODULAÇÕES LITERÁRIAS, CIENTÍFICAS E CULTURAIS*
}

\section{The Biology into monteiro lobato's child and teenage literature: literary, scientific and cultural modulations}

Fabiana Aparecida de Carvalho ${ }^{1}$

\begin{abstract}
Resumo: A tessitura deste trabalho abarca os traços da Biologia presentes em duas obras infanto-juvenis de Monteiro Lobato. Os entendimentos acerca dos traços biológicos como evolução, seleção natural, tamanho, classificação e organização natural se hibridizam, mesclam-se a outros discursos e significados e apontam relações e significações que se dão entre os espaços - diferenças - dos múltiplos conhecimentos. Ao reconhecer que a Biologia participa dessa Literatura, construiu-se um olhar para seus significados que são (re)criados em relação às diferenças, não funcionando como decalque, cópia de um campo cultural único ou suposto como original. Ao migrar para o texto, os significados culturais desses traços biológicos expandem o campo da escritura por uma interrupção e um espaçamento. Investigaram-se as relações de diferenças que se estabelecem entre Literatura e Biologia, e a intensidade das narrativas que trazem traços de crenças, valores, interesses políticos no discurso científico, e que são arrastados para a Literatura, num trajeto híbrido e nômade.
\end{abstract}

Palavras-chave: Biologia. Literatura. Traços biológicos. Monteiro Lobato.

\begin{abstract}
The texture of this essay encompasses the traces of Biology present in two Monteiro Lobato's child and teenage literature. The understanding about biological traces such as evolution, natural selection, size, classification and natural organization flow and mix with other themes and meanings and point out relationships and senses that occur among spaces - differences - of multiple Knowledge. Recognizing that Biology participates of this literature, we were able to construct a view into meanings that are (re) created in relation to the differences, not functioning as mere patches, copies of a unique cultural field or supposes as original. By bringing cultural meanings of these biological traces to the texts, there is an expansion in the writing by means of interruptions and spacings. One can investigate the relationships of the differentiations that are established between literature and biology and the intensity of the narrations that bring the beliefs, values and political interests in the scientific speech and that are brought into the literature in hybrid and nomad direction.
\end{abstract}

Keywords: Biology. Literature. Biological traces. Monteiro Lobato.

\footnotetext{
* Elaborado a partir de Carvalho (2002).

${ }^{1}$ Licenciada em Ciências Biológicas. Doutoranda, Programa de Pós-Graduação em Educação para a Ciência, Faculdade de Ciências, Universidade Estadual Paulista (Unesp), campus de Bauru. Bauru, SP.

$<$ facarvalho@positivo.com.br>
}

${ }^{1}$ Rua Euzébio da Motta, 788, apto. 35

Juvevê - Curitiba, PR

$86.530-260$ 


\section{Trajetos nômades para cartografar a Biologia na cultura}

Saberes nômades... Saberes que tensionam e migram de uma instância cultural a outra, que ganham significados e dizem, em seus contextos, dos territórios de disputas políticas, sociais, culturais, objetivas e subjetivas. Saberes em passagens que ganham movimento no "entre - lugar", no espaço fronteiriço que não é, especificamente, um nem outro espaço, mas sim o espaço de criação de diferenças que podem ser cartografadas em nossos estudos e mapeamentos.

É interessante situar este artigo nesta afirmação preliminar, procurando romper com uma certa linearidade, e recriar os traços de um sentido nômade que vai caminhando por entre Cultura - Biologia e Literatura, tendo esses espaços como lugares de formação, lugares onde se apresentam os traços que lêem/descrevem Ciência, discursos, saberes; onde os terrenos de produções culturais marcam a diferença e as significações de múltiplos temas e abordagens, alguns dos quais diluídos em nossos discursos, falas e crenças cotidianas e acadêmicas.

A nomadologia - para utilizar o termo proposto por Deleuze e Guattari (1995) permitiu-nos realizar trajetos e composições de tessituras e passagens entre campos aparentemente, ou, propositadamente, desconexos, como também indagar sobre os entre - lugares: "Biologia e Literatura". Não nos interessa, aqui, buscar definições exatas sobre o que é Biologia e sobre o que é Literatura; fugimos de narrativas para, mais livremente, questionar os valores, as representações e os significados que demarcam, esses dois campos, como produções culturais.

Essa abordagem, organizada em torno da cultura e de seu papel constitutivo (na linguagem e nas representações), privilegia contornos diversos que possam desconstruir o óbvio, fornecendo, às pessoas, questões e formas de estranhamento que explicitem os significados partilhados culturalmente. Estes aportes são fundamentos dos Estudos Culturais em Educação que, com diversidade metodológica, caracterizam-se pela pluralidade de análises, tecendo redes dentro das quais se podem traçar múltiplos percursos e extrair conclusões variadas e ramificadas. Assim, as categorias e formas de análise revelam-se no instante em que teoria e prática se entrelaçam, associando-se a práticas e representações diversas, e a variados temas de investigação que podem ser utilizados para mesclar as categorias, como: raça/etnia, luta de classes/interesses, gêneros/identidades, produção tecnológica/ciência/ambiente; favorecendo deslocamentos que derrubam a visão de que há um único e verdadeiro parâmetro para referenciar o conhecimento.

Para caminhar um pouco mais adiante e relacionar os estudos das representações aos espaços de diferenças, focamos nossos referenciais nas perspectivas desconstrucionistas de Bennington e Derrida. Os autores postulam que a diferença só aparece na escrita, "obrigando-a a tomar como referência o seu próprio traço escrito [...] se ela quiser dizer da diferença" (BENNINGTON, DERRIDA, 1996, p. 58). A diferença só vai se constituir na relação com outras diferenças e antecipando os sentidos sempre em relação ao sentido subseqüente. Para esses autores, a diferença (ou traço) supõe uma remarcação na qual todo significante remete para outros significantes, não se chegando nunca a um significado transcendental, ou seja, nenhum significado remete apenas para si mesmo, ou ainda, "um significado não é mais que um significante posto numa certa posição por outros significantes" (BENNINGTON, DERRIDA, 1996, p. 34), que gera não sentidos, mas efeitos. 
A Biologia em obras infantis de Monteiro Lobato...

Nessa conceituação se nomeia o traço, "pois se todo elemento do sistema só possui identidade em sua diferença com relação aos outros elementos, cada elemento está marcado por todos esses que ele não é: ele traz portanto o traço deles" (BENNINGTON, DERRIDA, 1996, p. 62). A característica marcante do traço é, portanto, sua alteridade, nomear a inscrição do outro nele mesmo: "todo traço é traço de traço" (p. 60), encadeamento que se constitui na relação entre as diferenças.

À luz destas idéias, pudemos puxar alguns fios que foram moldando o formato das análises. Consideramos que a Biologia, dentro de uma construção social, articula-se com as diversas instâncias sociais que produzem conhecimentos. O diálogo, por assim dizer, entre Biologia e essas instâncias, dá-se em espaços de constantes tensões e negociações que geram relações entre as diferenças; diferenças baseadas nas passagens de significantes que se relacionam com outros e outros significantes e significados (conceitos, palavras, explicações, analogias etc.), permitindo que traços dos mais diferentes campos do conhecimento sejam capturados e significados novamente dentro de um contexto, como exemplo, nas obras literárias. Se os traços, como sistemas de representações e significações, desdobram-se em diversos outros, muito nos instigou a busca de elementos que respondessem as perguntas que nortearam a análise: Os traços da Biologia, em passagem por obras de Monteiro Lobato, somam-se e expandem-se em quais significações? Nas obras escolhidas, quais outros traços são arrastados de nossa cultura e somam-se aos significados do campo científico?

Essas indagações impulsionaram-nos a buscar inscrições, marcas e traços na produção de representações da Biologia, e apontar / construir significados que estão presentes na trama cultural das obras infanto-juvenis de Monteiro Lobato, especificamente: "A chave do tamanho" (CT) (LOBATO, 1964a) e "A reforma da natureza" (RN)2 (LOBATO, 1964b).

Quando lemos as obras de Monteiro Lobato, entendemo-las em um contexto do qual participam conceitos, explicações, interpretações (linguagem) e formas de ordenar a natureza que podem ser associadas à Biologia. Entretanto, estamos afirmando que encontrar esses elementos da Biologia na produção literária remete-nos a considerar que eles participam dos processos de significação da obra - quer sejam realizados pelos leitores ou pelo autor que podem ser, por exemplo, associados à fabulação, à regulação moral, à imaginação, ao faz de conta, às relações entre poder e saber.

Ao reconhecer que a Biologia participa desta produção cultural - a Literatura - e dentro da perspectiva dos Estudos Culturais, apostamos que os significados, dentro da obra, têm de ser criados. Eles não são decalcados de um campo suposto como original. Nessa criação - ou significação - produzem-se representações culturais, que também estamos considerando como híbridas, nômades e múltiplas. Elas não são, portanto, aprisionáveis, não têm um ou mais sentidos: o que podemos supor é que elas geram efeitos na organização da leitura e da escritura da obra.

Ao se apropriar de várias dimensões da Biologia para compor sua obra, Monteiro Lobato faz uso, consumo ou se apropria dessas "coisas culturais", dando-lhes forma, valor e significância. Segundo Wortmann (2001), os significados regulam e organizam nossas condu-

\footnotetext{
2 Para efeito de esclarecimento e orientação da leitura, iremos nos referir às obras de Monteiro Lobato por suas iniciais.
} 
tas e práticas, participando do estabelecimento de normas, regras e convenções por meio das quais é ordenada e governada a vida social. Em algumas situações, a Biologia participa, nos interstícios do texto, como um pano de fundo, na desarrumação das lógicas da história e das lógicas de uma ordem social, política e ideológica; ou de lógicas das coerências e relevâncias para o bem e para o progresso - que se atribuem às ciências.

A Biologia, entendida como produção cultural, é artefato utilizado para o desdobramento da escritura, para as paradas, para os intervalos que incidem sobre o espaço e sobre o tempo da leitura. Expande o campo por uma interrupção, um espaçamento, pois quando aparece no texto, carrega com ela traços de significados culturais. Quando se aproxima da evolução, da classificação, das relações ecológicas e adaptativas, Monteiro Lobato dá forma à Biologia, especialmente com explicações, compreensões de como transformar a natureza, discursos que tensionam com o prático, com o mais adequado etc. Nesse aspecto, embora se considerem tênues as fronteiras, é pelo que há de mais específico na sua produção literária que Lobato realiza essas passagens, esses deslocamentos da Biologia. Discursivamente, quando atravessam os corpos modeláveis do Visconde ou da Emília - brinquedos de crianças - a Biologia ganha valores diferenciados - tanto da instância de produção científica, quanto no enredo da obra. Talvez pudéssemos compreender que essa diferença consiste em retardar, reduzir o ritmo, incidir sobre o tempo, fundamentais para uma narrativa literária, como para outras produções artísticas como o cinema. A Biologia, neste ponto, é traço, significa também divergir, por meio de um adiamento a provocar encadeamentos e agenciamentos. Biologia, neste ponto, é "um instrumento de passagem, possibilita a presença. Multiplicar os intervalos, "testemunhar a diferença" (PEIXOTO, 1999, p. 242).

Muito embora os estudos sobre fabulação compreendam que ela se liga ao mundo pela busca de conhecimentos objetivos, por intermédio, por exemplo, das Ciências Naturais, a presença da Biologia, nessas obras, não trata de uma simples relação entre duas coisas (um interior e um exterior), mas do lugar onde elas ganham velocidade.

\section{Em passagem pelas obras, traços e significados em expansão}

"A chave do tamanho" conta a história da "maior reinação" do mundo, na qual Emília reduz, temporariamente, o tamanho das criaturas humanas. A trama desenvolve-se com o descontentamento - manifestado por todos do Pica-pau Amarelo - em decorrência dos acontecimentos da Segunda Guerra Mundial'3. Para reverter a lógica das relações de poder, numa associação de que a guerra seria desligada por uma chave que a regula, Emília parte para a "Casa das chaves" onde, aplicando o método experimental do Visconde (tentativa erro - tentativa - acerto), que opera como raciocínio dedutivo e hipotético, derruba acidentalmente a chave que governa o tamanho dos seres humanos.

\footnotetext{
${ }^{3}$ Ou seria o descontentamento de Monteiro Lobato que se hibridiza aos personagens, pois as publicações de CT e RN (originais) coincidem com a fase mais trágica da vida do escritor. É nessa época que ele se vê obrigado a acompanhar o fracasso de suas companhias editoriais, sofre com o clima de perseguição, imposto pelo Estado Novo de Getúlio Vargas - decorrente de seu posicionamento favorável às campanhas petrolíferas e siderúrgicas - a tensão econômica mundial instaurada pela $2^{\text {a }}$ Guerra e as complicações de saúde que culminaram em sua morte em 1948.
} 
A Biologia em obras infantis de Monteiro Lobato...

A aventura transcorre no "mundo biológico", forçando as personagens a se adaptarem às novas situações: "Que mundo este, santo Deus! - murmurou, muito atenta a tudo quanto se passava ao redor. É o tal 'mundo biológico' de que tanto o Visconde falava, bem diferente do "mundo humano" (CT, p. 32).

A descoberta do mundo biológico abre-se, desdobra-se em uma nova ordem das coisas e uma maneira de se viver longe das guerras entre os homens. Em desdobramentos do raciocínio de Emília, suas suspeitas e reflexões prepararam os demais envolvidos à situação pequenina e à vivência no mundo biológico. Depois de muitas reinações e experiências, os habitantes do Sítio votam em plebiscito para que a humanidade volte à condição do tamanho original.

A segunda obra, "A reforma da natureza", é pura fabulação. As obras da Emília são inspiradas com base na fábula do reformador da natureza, que considerava a natureza dona de tolices e erros. A fábula apresenta uma razão moral implícita ou explícita e, geralmente, é "protagonizada por animais, cujo comportamento, preservando as características próprias, deixa transparecer uma alusão, via de regra satírica ou pedagógica, aos seres humanos" (MASSAUD, 1995, s.p.). Mas é notável a ruptura que se dá nos exercícios de saberes e vontade de Emília. Perspicaz, a boneca subverte o objetivo moral da fábula, tornando-a sem moralidade, sem ordem, linearidade ou hierarquia, ou seja, fratura-a e a expande em possibilidades de quebra dos ordenamentos esperados, e fornece outros agenciamentos para o leitor.

[...] Sempre achei a natureza errada - disse ela - e depois de ouvir a história do Américo Pisca-Pisca, acho-a mais errada ainda [...] Tudo que é demais está errado. E quanto mais eu estudo a natureza mais vejo erros [...] É tudo assim. Erradíssimo. Eu, se fosse reformar o mundo, deixava tudo um encanto, e começava reformando essa fábula. (RN, p. 168)

[...] O fabulista era um grande medroso; queria fazer uma fábula que desse razão ao seu medo de mudar [...] Já reformei a fábula. (RN, p. 211)

Há reformas praticamente em quase tudo: pássaros-ninho, laranjas sem cascas, vacas com torneirinhas para ordenha, que acabam por ser desfeitas sob a argumentação precisa de Dona Benta - "A natureza sabe o que faz". Em antítese, o Visconde entusiasma-se com a fisiologia e procede as experiências, que também geram criaturas incríveis, com projeção e destaque no mundo científico.

\section{Os desdobramentos da Biologia nas obras escolhidas}

As personagens do Sítio do Pica-pau Amarelo são multimodulados, seres incompletos a se realizarem nos encadeamentos dos espaços entre criação e interpretação. Como "gentes" inacabadas permitem conexões e agenciamentos, desdobram-se em novas encarnações e personalizações que equilibram a diversão e a instrução, seja pela possibilidade do faz-deconta, seja pelo fato de que, no "Sítio", os sabugos de milho, as bonecas de pano e alguns 
outros animais tornam-se gente. Um devir que se dá por rupturas e prolongamentos, um devir que se dá por permanência na metamorfose ${ }^{4}$ - espaçamento que oscila entre duas formas: de um lado, aquela que permanece, de outro, aquela que se inventa e se transforma; um devir em diversas direções - devir brinquedo/devir ser criança.

É pelo devir que transcorrem as duas histórias infantis que escolhemos, devir imaginação, que se articula a múltiplos modos de soluções de problemas criados pelas personagens em ação, e pelos significados, antecipados pelos leitores e leitoras, que entram na trama, seja por expectativa, seja por entendimento. Maneiras de agir, criar e fazer que puxam a Biologia para articular histórias e a ecoam, na relevância das situações, não como Biologia enciclopédica, mas como estratégia criativa a desdobrar-se em enredo e antecipações que geram - além de explicações, estratégias e atitudes.

Um traço da Biologia - posto em devir - confere à Emília, já em sua origem e desenvolvimento, caráter e ações quase humanas; aliás, é ela quem mais reflete a incessante remarcação de traços do outro - outros no mesmo. O devir da personagem inicia-se no instante em que ela tomou uma pílula e "foi evoluindo e insensivelmente passou de boneca a gente de verdade, conservando o tamanho original - quarenta centímetros de altura" (CT, p. 1). O traço evolução cultural - a fala - marca passagem do significado de transformação. É tentador afirmar que esta representação de "evolução" atende, aqui, a uma certa intenção de mudança que se deixa completar, o desdobramento de um brinquedo em gente de verdade, uma condição para enfrentar com êxito todas as situações problemas, permitir trajetórias e ações indeterminadas de usos e consumos que subvertam as relações previamente esperadas em surpresas. Parece-nos original pensar nessa condição como conexões entre os leitores e sistemas de traços que trazem significados do meio científico e de outras culturas que, em tensões e diferenças, desdobram-se na fábula que gera outros significados sociais.

A aventura da personagem Emília pelo chamado "mundo biológico" inicia-se com os desdobramentos do traço "tamanho", traço que se expande por sua relatividade: aumento - diminuição. Emília também põe em xeque a lógica de dominação ao contestar os sistemas reinantes e articular suas aventuras.

- Se todas as criaturas ficaram pequeninas como eu fiquei, então o mundo inteiro deve estar na maior atrapalhação e com cabeças tão transtornadas quanto a minha. Mas a guerra acabou! Ah, isso acabou! Pequeninos como eu, os homens não podem mais matar-se uns aos outros, nem lidar com aquelas terríveis armas de aço. O mais que poderão fazer é cutucar-se com alfinetes ou espinhos. Já é uma grande coisa $[\ldots]$ Pensou, pensou, pensou.

- Sim, eu mexi na Chave do Tamanho e todas as criaturas vivas ficaram pequenas porque seria absurdo haver uma chave só para minha pessoa. (CT, p. 12-3)

${ }^{4}$ Expressão criada por André Malraux (apud FREITAS, 1996, p. 229). 
A Biologia em obras infantis de Monteiro Lobato...

Esse movimento instaura a nova ordem que foge da totalidade da guerra, antigos entendimentos e soluções para o mundo passam a ser idéias inúteis e perigosas. As novas experiências, que surgem com a diferença do tamanho, vão puxando traços como a relação "ataque - defesa" para compor diferentes significados de perigo e sobrevivência e gerar atitudes ilustradas pelos desdobramentos do raciocínio e informações: "Ora, a mudança do tamanho da humanidade vinha tornar as idéias tão inúteis como um tostão furado [...] A "idéia-deleão" era dum terrível perigosíssimo animal, comedor de gente; e a "idéia-de-pinto" era a dum bichinho inofensivo". Agora é o contrário. O perigoso é o pinto” (CT, p. 14).

Ramificações que vão se constituindo em linhas de rumo; dobras que fogem de uma observação simplista baseada na apresentação de leis e fenômenos naturais expandem a aventura, criam possibilidade para a dúvida e a perplexidade da personagem; dobram-se ou desdobram-se em discursos inicialmente fundamentados pelos traços da Biologia - "seleção natural" - que empurra o "aperfeiçoamento do sistema" - garantia de sobrevivência no mundo biológico regido pela "lei do quem pode mais":

Que mundo este, santo Deus! - murmurou, muito atenta a tudo quanto se passava ao redor. É o tal 'mundo biológico' de quem tanto o Visconde falava, bem diferente do 'mundo humano'. Diz ele que aqui quem governa não é de nenhum governo como soldados, juízes e cadeias. Quem governa é uma invisível Lei Natural. E que lei natural é essa? Simplesmente a Lei do Quem Pode Mais. Ninguém neste mundinho procura saber se o outro tem ou não razão. Não existe a palavra justiça. A natureza só quer saber de uma coisa: quem pode mais. O que pode mais tem o que quer, até o momento em que apareça outro que possa ainda mais e lhe come tudo. E por que essa maldade? O Visconde diz que é por causa duma tal Seleção Natural, a coisa mais sem coração do mundo mas que sempre acerta, pois obriga todas as criaturas a irem se aperfeiçoando. 'Ah, você está parado, não se aperfeiçoa, não é?' Diz a Seleção para um bichinho bobo. 'Pois então leve a breca'. E para não levar a breca, o bichinho trata de inventar toda sorte de defesas e astúcias. (CT, p. 28-9)

Parece-nos importante atentar para a forte questão discursiva do traço "Lei do quem pode mais - Seleção Natural". O mundo biológico não é institucionalizado, no entanto, leis naturais, como a seleção, não são antes tomadas como fenômenos da natureza, mas tornamse princípios reguladores, como se fosse possível equiparar à seleção natural os papéis de juiz e carrasco. Esse traço da Biologia é trazido à fala da personagem, porém o traço - posto na relação que o difere e que o transforma em efeito, (re) significa não as definições biológicas de seleção, mas no seu mesclado, o traço - efeito fala de cultura ou da "esfera pela qual a cultura é governada" (HALL, 1997, p. 34).

Na história, os traçados da Biologia tensionam-se e se ramificam, posicionam-se como pano de fundo que vai sustentando toda a fabulação e a explicação que, sem esses efeitos de traços, perderiam toda graça da "inteligência como estratégia para adaptar-se ao pequeno mundo". 
- Tenho que arranjar uma arma qualquer. Há feras muito perigosas nesta mata. [...]

- E se me armasse dum espinho?

Mas como arrancar um espinho daqueles? Nem com a força de cem Emílias, quanto mais com a de uma só. E ficou de nariz para o ar, namorando aquele tremendo arsenal de lanças, até que lhe veio uma idéia. "Impossível que aqui pelo chão não haja algum espinho velho de alguma folha caída", e pôs-se a procurar. Foi feliz. Encontrou uma palmatória já desfeita pelo apodrecimento, mas com os espinhos em muito bom estado. Escolheu o menor e pronto.

- Estou um D. Quixote, com esta tremenda lança - disse, pondo a arma debaixo do braço, tal qual fazia D. Quixote.

Logo adiante estava uma aranha quase do seu tamanho, encorujada na teia, à espera de bichinhos incautos. Vendo aproximar-se aquele inseto desconhecido a aranha armou o bote; mas Emília de lança em riste, não lhe deu importância - foi chegando. Ao atirar-se contra ela, a aranha cravou o ventre no espinho. Esperneou, berrou, mas não teve remédio senão ir encolhendo as pernas e morrendo. A primeira vitória de Emília em pleno "mundo biológico" encheu-a de orgulho. Estava demonstrando aos seus colegas o valor da inteligência. (CT, p. 35-6)

Nas ações de Emília, enquanto ela descobre e se aventura pelo mundo biológico, o traço adaptação diferencia-se em: esperteza, inteligência dedutiva, possibilidade de vitória e conquista, ajeitar-se às situações - "Adaptar-se quer dizer ajeitar-se às situações. Ou fazemos isso, ou levamos a breca. Estamos em pleno mundo biológico, onde o que vale é a força ou a esperteza" (CT, p. 45).

São efeitos explicativos que não poderiam ser saltados da trama. Lembram-nos das "inserções" nos manuais e livros escolares, trazem o contraponto de caráter didático via diversão. São traços da Biologia puxados para a resolução das situações-problema, híbridos de informação, formação e diversão, que orientam as estratégias de defesa, explicadas por Emília, que as descobre, em princípio, por suas próprias experiências e deduções no "mundo biológico"; e, depois, por meio de sua voz, que traduz toda a nova situação às crianças que estão na aventura, subvertendo-as, quebrando a lógica centrada na "relação" de sobrevivência dos mais fortes - significados que percorrem discursivamente e justificam hierarquias sociais.

É curioso dizer do conjunto de significados que se agregam à passagem do traço mimetismo - fingimento, armamento, estratégias de defesa em efeitos contrários, traços que falam de "quebra", rompimento e instauram um novo efeito: "a defesa do fraco contra o forte - mas do fraco esperto" (CT, p. 76-7), daquele que manifesta vontade de potência e luta, mas que luta pela sobrevivência, pela vida.

- Com a inteligência ou a astúcia, como fazem tantos insetos deste mundo. O Visconde já me explicou isso muito bem. Uma da melhores defesas, por exemplo, se chama mimetismo. 
A Biologia em obras infantis de Monteiro Lobato...

- Mime o quê?

- Tismo. Mi-me-tis-mo. Quer dizer imitação. Uns imitam a cor dos lugares onde moram. Se moram em pedra, imitam a cor da pedra. Se moram em grama, como os gafanhotos, imitam a cor da grama. Por quê? Porque desse modo os inimigos os confundem com a grama. E há os que imitam a forma das folhas das árvores ou dos galhinhos secos.

- Eu já vi um desses - lembrou Juquinha. - O Totó apareceu lá em casa com um galhinho seco na mão. "Que é isto?" me perguntou. Eu olhei e respondi: "É um galhinho seco". Totó riu-se e largou o galhinho no chão - e sabe o que aconteceu? O galhinho começou a andar! Era um bicho pernudo, cascudo, que imitava galho seco.

- Pois é. Estava "mimetando" um galho seco. Mimetismo é isso. Não conhece aquelas borboletas carijós que se sentam nas árvores musguentas e ficam ali quietinhas, tal qual um desses musgos cinzentos? Musgos, não. Líquen. Líquen! O visconde não quer que a gente confunda musgo com líquen. Decore! [...] - Pois é isso. Esses fingimentos são as armas de tais insetos. É a defesa do fraco contra o forte - mas do fraco esperto! (CT, p. 76-7)

Fatos ordenados por Emília expandem-se em questionamentos e valores ao esboçarem traçados não esperados como os presentes nas descrições meramente conteudistas. Esse ponto de vista aproxima-se daquilo que Vierne denomina de "efeito Júlio Verne", mostrando que os recursos literários, utilizados na "inclusão, nítida e confessa, da Ciência no discurso literário" (VIERNE, 1994, p. 87), atribuirão novos significados culturais à Ciência e à própria Literatura. Entendemos, com a autora, que nas ligações tempestivas entre Ciência e Literatura está se assegurando, na remarcação dos traços biológicos e de suas técnicas, a passagem de grandes mitos e temas sociais importantes, gerando a expansão do imaginário que se serve da Ciência "para tecer em conjunto os diversos saberes e os diversos códigos numa visão pluralística e multifacetada do mundo" (CALVINO, 1990, p. 127).

É próprio de esse efeito inserir e atribuir significado à Ciência, procurando compor certo hibridismo entre aquilo que nos é dado como Biologia e aquilo que nos é dado como significado cultural.

As proporções dos seres ganham novos direcionamentos ao se vincularam com valores e discursos sociais nos quais a hierarquia de dominância está associada ao crescimento vertical dos seres vivos. No mundo humano/cultural os critérios que definem o poder do homem sobre demais povos e seres são os tamanhos:

Cheguei até cá para dizer uma coisa só - que o tamanho morreu. E quem acabou com ele é a única pessoa que pode novamente restituir aos homens o antigo e querido tamanho - aquele tamanho malvado, porque se não fosse ele os homens não teriam sido maus como foram, fazedores de guerras, incendiadores de cidades, afundadores de navios, judiadores de judeus. (CT, p. 42) 
Pensando no efeito de tamanho associado ao poder, buscamos argumentos que pudessem explicar a passagem dessa categoria biológica na justificativa de práticas sociais e culturais. Não é a primeira vez que observamos os efeitos desse sistema de traços. A significação de um mundo ordenado, com organismos desde as formas "mais baixas" até as "mais altas", está profundamente enraizada em nossa cultura.

Discursos efetivos sobre tamanho e proporção referem-se às metáforas de dominância e supremacia. Esta afirmação é uma criação social que se sobressai nos discursos incorporados pelas instâncias culturais, mas que também podem ser arrastados de alguns entendimentos biológicos, como "acreditar que as classes de vertebrados podem ser dispostas numa escala perfeccionista que vai dos peixes aos mamíferos, passando pelos níveis intermediários de anfíbios, répteis e pássaros" (GOULD, 1997, p. 209).

Um exemplo é extraído do artigo de Semonin (1997), que verifica o impacto da imagem de dinossauros como "gigantes carnívoros" numa pré-história definida pela selvageria, alertando-nos para as representações enraizadas desses animais pré-históricos, como donos de um império cujo reinado é caracterizado pelos domínios e força diante das demais espécies (SEMONIN, 1997, p. 171-82).

É dentro de uma espécie de inversão dimensional (tamanho) que a Biologia tem passagem pela Chave do tamanho. Nos diálogos de Emília e do Visconde, que desmontam o previsível, desterritorializando-o com base em seus conhecimentos e observações das personagens, as representações são invertidas no contexto da história, pois ao diminuir o tamanho, proporcionalmente menores serão as forças, as relações de poder, os aparatos bélicos, o totalitarismo, traços de governos e regulação social.

Veja! - Exclamou o Visconde filosoficamente. Esta gente, que era a mais terrível e belicosa para o mundo e estava empenhada numa guerra para a conquista do planeta, ainda é mentalmente a mesma quero dizer, ainda sente e pensa da mesma maneira. E ainda sabe tudo quanto aprendeu. Os químicos sabem fazer prodígios com a combinação dos átomos. Os físicos e mecânicos sabem todos os segredos da matéria. Os militares sabem todos os segredos da arte de matar. Mas como perderam o tamanho, já não podem coisa nenhuma. Sabem, mas não podem. Que coisa terrível para eles!

- Estou vendo que a grande força dos homens estava no tamanho disse Emília. O tamanho era como o cabelo de Sansão. Quando Dalila cortou o cabelo de Sansão, o coitado perdeu toda força.

- Exatamente - concordou o Visconde. O tamanho era tudo, isto é, todo o aparelhamento mecânico da humanidade fora feito para os homens daquele tamanho.

[...] - Aqui morava o ditador que levou o mundo inteiro a maior das guerras, e destruía cidades e mais cidades com os seus aviões, e afundava os navios com seus submarinos, e matava milhares e milhares de homens com seus canhões e suas metralhadoras - o homem mais poderoso que jamais existiu. Tudo isso por que? Porque tinha oito palmos e meio de altura. Assim que foi reduzido a quatro centímetros, todo o seu poder evaporou-se. (CT, p. 157-8) 
A Biologia em obras infantis de Monteiro Lobato...

Ao desarrumar essa lógica, o faz-de-conta da personagem Emília nos transporta para o mundo de outras imensidades, a imaginação é o trilho pelo qual rola a informação hibridizada pelo real, pelo raciocínio e imaginário. As diversões de alteração de tamanho servem para introduzir outros tempos e espaços, significam mudar de perspectiva, deslocar o olhar da realidade que vivemos e gerar efeitos que nos conduzam através das experiências e diferenciações das dimensões de escala e da diversidade de criaturas.

Emília (re) significa uma relação (que pode ser também a nossa) com o pequeno - o outro, outros - no mundo considerado biológico. Esse movimento agencia, encadeia, entre outras coisas, olhares, com certo estranhamento, para a "representação normatizadora" do tamanho - naturalizada em nossas sociedades e cotidianos, que continuamente modelam e constituem nossos significados de maior-melhor, maior-poder, maior-beleza, maior-domínio, etc. Se, por um lado, lemos a regulação moral pela "seleção", por outro, temos efeitos do traço "tamanho" que trazem encadeamentos mais abertos: quebra, ruptura e transgressão das "regulações normativas que constituem os sujeitos e guiam as ações físicas para criar uma ordem no mundo" (HALL, 1997, p. 42). A perda do tamanho posta em relação com a perda da vergonha, ou, diferenciando-se vergonha como norma, permite o aparecimento do "devir" criança, inocência.

- Que coisa curiosa! - Exclamou enquanto se esfregava. - Estou nua e não sinto a menor vergonha. Será que isso de vergonha depende do tamanho das criaturas? Deve ser, porque entre os homens a vergonha era só para os adultos. As criancinhas novas não se mostravam vergonha nenhuma nem ninguém se ofendia de vê-las nuas. Aprendi mais essa: vergonha é coisa que depende do tamanho. (CT, p. 42)

O traço "evolução", mais uma vez, se faz presente para explicar as relações e criações do homem por meio da cultura. Buscando adequar-se à nova ordem, Emília partilha de suas compreensões não somente com o Visconde, mas com outros cientistas que elaboram explicações e justificativas para que a nova civilização permaneça. A história da humanidade, nos feixes de traços que se estabelecem, a partir da descoberta e do uso do fogo, é significada, no fragmento abaixo, como uma interessante e distinta reflexão a respeito de suas conseqüências para a evolução do Homo sapiens, tendo como efeito marcar, por meio da fala de um "homem da ciência", as potencialidades da invenção da diferença nos tamanhos dos seres vivos.

Enquanto o homem não descobriu o fogo, viveu muito bem dentro da lei biológica, a civilizar-se lentamente. Veio o fogo e tudo mudou começou o galope sem fim. Que eram aqueles monstruosos arranhacéus deste país, que era a blitzkrieg dos alemães, que era nossa pressa de transporte e comunicação por meio de trens, aviões, navios, telégrafos, telefone e rádio, se não uma conseqüência do fogo? Apaguese o fogo e tudo desaparece. (Disse o doutor Barnes).

- Foi o fogo que permitiu aos homens viverem em todos os climas e não apenas nos que lhes convinham naturalmente. Sem o fogo o homem só viveria nas zonas temperadas, as boas, e nunca nas zonas 
Carvalho, F. A.

frias. E portanto haveria menos gente na Terra - outra enorme vantagem tanto para o próprio homem como para os animas. E há ainda outro aspecto muito importante do fogo: os seus efeitos na alimentação humana. Graças ao fogo o homem pode tornar comestíveis muitas coisas que não eram, e isso ainda aumentou a população humana no planeta, porque aumentou enormemente as possibilidades de alimentação. De modo que do fogo veio o calamitoso aumento da população humana, não só permitindo a invasão das regiões frias, como também transformando em comestíveis coisas que não eram naturalmente comestíveis. Quanto mais espaço vital e mais comida, mais gente.

[...] Estou convencido de que a desgraça da velha civilização veio das conseqüências sociais do fogo. Sempre pensei assim, porque sempre vivi na terra mais atormentada pelas reinações do fogo e do ferro: essa infinidade de máquinas que aqui na América nos fazia tropicar num galope sem fim - para que, meu Deus, para chegar ao que? Imaginem, pois, o meu gosto quando sobreveio este súbito fenômeno da redução do tamanho - o maravilhoso remédio para o caminho errado em que o Homo sapiens se havia metido desde a descoberta do fogo. (CT, p. 178-81)

A "evolução cultural", se apagada, ou melhor, se apagado tudo que é originado do fogo - artefato antibiológico -, poderíamos voltar a um estado mais próximo do natural. Puxando um fio para entrelaçar a essa questão, é importante registrar a passagem do discurso de antagonismo entre "homem - natureza" ou "natureza - cultura". A presença do traço "tamanho" marca, por um lado, as significações de um desenvolvimento cultural pautado na tecnologia desencadeada pela descoberta do fogo; por outro, a necessidade de retorno ou aproximação de regras de utilização da natureza mais primitivas, que nos harmonizassem com animais e demais seres e condições do mundo natural. O conhecimento - "conseqüência social do fogo" - passou a ser uma forma de poder constantemente usada como justificativa para a superioridade do homem sobre a natureza e do homem sobre o homem.

Ler obras de Monteiro Lobato, como contexto do qual participam conceitos, explicações, interpretações e formas de ordenar a natureza que podem ser associadas à Biologia, é uma operação que, sem dúvida, doma, sobrecodifica, metrifica, neutraliza, mas também se propaga em significados diversos. À fabulação e ao faz-de-conta podemos associar esses movimentos, interpretá-los como lugares onde os traços ganham velocidade e a Biologia se dobra em exterioridade e interioridade, junto ao próprio da literatura de Monteiro Lobato, que é a invenção e a imaginação.

Enquanto que na obra "Chave do tamanho" os traços adaptação, seleção, classificação eram elementos ordenadores da trama e reconhecidos por Emília como condições no mundo biológico - natureza; na obra "A reforma da natureza" esses mesmos traços são desarranjados, postos em diferença pela personagem, que os desrespeita, os dissimula e os (re) interpreta, 
A Biologia em obras infantis de Monteiro Lobato...

colocando-os em situações de questionamento; significados que são postos em relação com outros significados e significantes - diferenças e efeitos.

Em um espaço ativo de criação, as coisas vão se completando. Discursivamente, quando os significados atravessam os corpos modeláveis de Emília e ou do Visconde, a Biologia ganha valores diferenciados tanto da instância de produção científica, quanto no enredo da obra. Talvez essa diferença consista em retardar, reduzir o ritmo, incidir sobre o tempo e o espaço, fundamentais para a narrativa literária e outras produções artísticas como cinema, fotografia ou a pintura.

$\mathrm{Na}$ reforma realizada pela Emília, a natureza é vista como erro e seu funcionamento não é, por assim dizer, um modelo e norma a serem seguidos socialmente. A Ciência entra na trama, ponto e traço de produções que são puxadas para justificar a visão prática e utilitária de Emília, que busca corrigir a natureza com a lógica da simplificação e de sua objetividade. "Enfeites são inutilidades. Não quero saber dos enfeites nas minhas reformas. Tudo há de ter uma razão científica [...] Eu quero corrigir a natureza, quero melhorá-la!” (RN, p. 198).

Um faz-de-conta que tudo resolve, no plano das histórias, e possibilita aos leitores e leitoras a decisão por um senso ético, ao inscrevê-los em uma posição de opinar, participar, passear por sua fantasia e pela fantasia da escrita. Situações, por exemplo, em que o traço "adaptação" é puxado para causar efeitos e posicionamentos éticos são tencionadas; ponto e contraponto, duas racionalidades postas em conflito: a opção pela reforma, de Emília - senso prático, e a opção pelo bom senso, representado por Dona Benta, além de uma indicação de que a Ciência não representa necessariamente a natureza.

A característica da fábula de facultar ao leitor envolver-se, na segurança de um mundo do faz- de-conta, em situações de limite de certo e errado, sem a imposição de uma verdade única, expande-se como trajetória, tática que opera em liberdade de escolher os significados culturais - que ressoam no leitor/a, sejam eles para falar da moral, sejam para falar de uma ausência de moral ${ }^{5}$. A inventividade, entretanto, empresta à Ciência explicações e compreensões de como transformar a natureza, discursos que tensionam com o prático, com o mais adequado, com o utilitarismo, mas em outras segmentações e fugas, possibilitando a quebra de uma lógica previsível e permitindo o máximo de reforma híbrida; e nessas ações vemos todas as transformações que vêm de novas e inesperadas combinações de seres vivos, idéias malucas, aparatos mecânicos, o outro continuando a ser o mesmo e a diferença (animal - máquina, animal - coisa, animal - utensílio; personagens antropomórficas: bonecos modeláveis - crianças).

E é dessa maneira que a novidade entra no mando: nos diálogos pautados com critério científico, discutido por Emília e pela criança que a ajuda na reforma (A convite de Emília, a personagem Rã - "menina que também não concorda com os absurdos da lógica vigente", é a representação do/a leitor/a convidado/a a interagir na trama); e, com muito critério, passam as duas a realizar as transformações, pois "reforma não é brincadeira", precisa da orientação de um fazer da ciência que justifique e gere o controle e a previsibilidade dos híbridos entre natureza e cultura.

${ }^{5} \mathrm{~A}$ ausência de moral não é a imoralidade, mas uma condição que faculta aos leitores e leitoras diferentes posicionamentos. 
Lá se foram as duas para o pastinho da vaca Mocha, que estava pachorramente mascando umas palhas de milho. Ficaram diante dela, de mãos à cintura, discutindo a reforma [...]

- Não - declarou Emília. - Muito complicado. Na Mocha quero umas reformas úteis para ela mesma e não para criaturas que a exploram. Vou por a cauda da Mocha bem no meio das costas, porque assim como está só alcança metade do corpo. Como pode a coitada espantar as moscas que lhe sentam no pescoço, se o espanador só chega às costelas? Tudo errado [...]

E plantou a cauda da Mocha no meio das costas de modo que pudesse espantar as moscas do corpo inteiro: norte, sul, leste, oeste. E passou as tetas para os lados, metade à esquerda, metade à direita.

- Assim podemos tirar leite de um lado enquanto o bezerrinho mama do outro. Reforma não é brincadeira. Precisa ciência. (RN, p. 214-5)

Os planejamentos de Emília marcam a passagem do traço "fazer ciência" como modelo para se fugir das mudanças organizadas por certos governos; esse fazer é a legitimação de que nada seja feito ao acaso e às tontas. "Emília aprendeu a planejar a fundo qualquer mudança nas coisas, por menos que fosse. Viu que isso de reformar às tontas, como fazem certos governos, acaba sempre produzindo mais males do que bens" (RN, p. 250).

Imagens diversas presentes nos territórios científico e literário nos fazem refletir sobre as produções culturais e do quão elas estão envoltas de interesses políticos, ideológicos, ficção e verdades; feixe de traços e desdobramentos que não param de expandir em espaços contingentes, ainda culturalmente falando.

Capturados pelo "faz-de-conta" e pelos significados sociais a Biologia - Ciência não deixa de (re) significar diferentes traços e efeitos, mesmo nas obras escolhidas, envoltas pelo seu próprio - a dimensão da fantasia, há sempre disputas e tensões que se apropriam de representações culturais; sempre há uma (re) criação que implica na escolha de leituras, temas, interpretações, recusas e supressões de textos por aqueles que usam das formas discursivas para transformar ou fixar algumas de nossas práticas. 
A Biologia em obras infantis de Monteiro Lobato...

\section{Referências}

AMARAL, M. B. Representações da natureza e a educação pela mídia. 1997.

Dissertação (Mestrado em Educação) - Universidade Federal do Rio Grande do Sul, Porto Alegre, 1997.

BENNINGTON, G.; DERRIDA, J. Derrida. Rio de Janeiro: Jorge Zahar., 1996.

Outros... com textos e passagens - traços biológicos em obras de Monteiro

Lobato. 2002. Dissertação (Mestrado em Educação) - Faculdade de Educação,

Universidade Estadual de Campinas, Campinas, 2002.

CALVINO, I. Por que ler os clássicos. São Paulo: Companhia das Letras, 1990.

DELEUZE, G.; GUATTARI, F. Mil platôs - capitalismo e esquizofrenia. Rio de Janeiro: Ed. 34, 1995. v. 1.

FREITAS, M. T. Escrever é reescrever: vide André Malraux. In: HEISE, E. (Org.).

Facetas da pós-modernidade. São Paulo: FFLCH/USP, 1996. p. 27-33.

GOULD, S. J. Darwin e os grandes enigmas da vida. São Paulo: Martins Fontes, 1997.

HALL, S. A centralidade da cultura: notas sobre as revoluções culturais do nosso tempo. Educação \& Realidade, Porto Alegre, v. 22, n. 2, p. 15-46, 1997.

LOBATO, M. A chave do tamanho. São Paulo: Brasiliense, 1964a. (Coleção Obras Completas de Monteiro Lobato).

A reforma da natureza. 4. ed. São Paulo: Brasiliense, 1964b. (Coleção Obras Completas de Monteiro Lobato).

MASSAUD, M. Dicionário de termos literários. São Paulo: Cultrix, 1995.

MELLONI, R. M. O imaginário e o ideário de Monteiro Lobato: um estudo antropológico. 1995. Tese (Doutorado em Educação) - Faculdade de Educação, Universidade de São Paulo, São Paulo, 1995.

PEIXOTO, N. B. Passagem da imagem: pintura, fotografia, cinema, arquitetura. In: PARENTE, A. (Org.). Imagem máquina: a era das tecnologias do virtual. Rio de Janeiro: Ed. 34, 1999. p. 237-52.

PENTEADO, J. R. W. Os filhos de Lobato: o imaginário infantil na ideologia do adulto. Rio de Janeiro: Dunya/Qualitymark, 1997.

PRIGOGINE, I. Science, reason and passion. Leonardo, New York, v. 29, n. 1, p. 39-42, 1996.

SANTOS, L. H. A Biologia tem uma história que não é natural. In: COSTA, M. V. (Org.). Estudos culturais em educação: mídia, brinquedo, Biologia, Literatura, cinema. Porto Alegre: Ed. Universidade/UFRGS, 2000. 
SEMONIN, P. Empire and extinction: the dinosaur as metaphor for dominance in prehistoric nature. Leonardo, New York, v. 30, n. 3, p. 171-82, 1997.

VEIGA-NETO, A. Michel Foucault e os Estudos Culturais. In: COSTA, M. V. (Org.). Estudos Culturais em Educação: mídia, brinquedo, Biologia, Literatura, cinema. Porto Alegre: Ed. Universidade/UFRGS, 2000. p. 37-69.

VIEIRA, A. S. Um inglês no sítio de dona benta - estudo da apropriação de Peter Pan na obra infantil lobatiana. 1998. Dissertação (Mestrado em Lingüística) - Universidade Estadual de Campinas, Campinas, 1998.

VIERNE, S. Ligações tempestuosas: a ciência e a Literatura. In: A ciência e o imaginário. Brasília: Editora Universidade de Brasília, 1994. p. 79-96.

VILELA, E. Corpos inabitáveis - errância, filosofia e memória. In: LARROSA, J.; SKLIAR, C. (Orgs.). Habitantes de Babel - políticas e poéticas da diferença. Belo Horizonte: Autêntica, 2001. p. 233-54.

WORTMANN, M. L. C. O uso do termo representação na Educação em Ciências e nos estudos culturais. Pro Posições, Campinas, v. 12, n 1, p. 151-61, 2001.

Atravessando os limites da Educação em Ciências. In: ENCONTRO DE PERSPECTIVAS DO ENSINO DE BIOLOGIA, 7., 2000, São Paulo. Coletânea... São Paulo: FEUSP, 2000. p. 680-3.

Artigo recebido em novembro de 2007 e aprovado em julho de 2008. 